\title{
Clinical Study \\ Determinants of Intravascular Resistance in Indian Diabetic Nephropathy Patients: A Hospital-Based Study
}

\author{
Anubhav Thukral, ${ }^{1}$ Manish Mishra, ${ }^{1}$ Vaibhava Srivastava, ${ }^{1}$ Hemant Kumar, ${ }^{1}$ \\ Amit Nandan Dhar Dwivedi, ${ }^{2}$ Ram Chandra Shukla, ${ }^{2}$ and Kamlakar Tripathi ${ }^{1}$ \\ ${ }^{1}$ Department of Medicine, Institute of Medical Sciences, Banaras Hindu University, Varanasi 221005, India \\ ${ }^{2}$ Department of Radiodiagnosis, Institute of Medical Sciences, Banaras Hindu University, Varanasi 221005, India \\ Correspondence should be addressed to Kamlakar Tripathi, kamlakar_tripathi@yahoo.co.in
}

Received 31 January 2011; Revised 8 April 2011; Accepted 12 April 2011

Academic Editor: Marc A. Passman

Copyright (C) 2011 Anubhav Thukral et al. This is an open access article distributed under the Creative Commons Attribution License, which permits unrestricted use, distribution, and reproduction in any medium, provided the original work is properly cited.

\begin{abstract}
Aims and Objectives. Metabolic dysregulation has failed to explain clinical variability of patients with diabetic nephropathy and hence a renewed interest emerged in haemodynamic factors as determinant of progression and development of diabetic nephropathy. We therefore studied for various factors which can correlate with raised renal vascular resistance in diabetic nephropathy. Material and Methods. Renal vascular resistance was measured in patients with established and incipient diabetic nephropathy and compared with controls using noninvasive color Doppler examinations of intrarenal vasculature. Results. Renal vascular resistance correlated with age, duration of disease, GFR, serum creatinine, and stage of retinopathy. Renal vascular resistance was significantly reduced in patients on treatment with RAAS inhibitors and insulin, than those on OHA and antihypertensives other than RAAS inhibitors. Conclusion. The study implies that renal vascular resistance may help identify diabetics at high risk of developing nephropathy, and these set of patients could be candidates for RAAS inhibition and early insulin therapy even in patients without albuminuria.
\end{abstract}

\section{Introduction}

Diabetes and its complications pose an immense amount of social and economic burden on the health infrastructure and resources throughout the globe. Diabetic nephropathy is the single most common cause of end-stage renal disease (ESRD) throughout the globe accounting for a whooping 25-45\% of all patients enrolled in ESRD programmes [1]. Diabetic nephropathy is also a leading cause of chronic kidney disease (CKD) in India accounting for about 30\% of all CKD patients [2]. Recent estimates suggest that soon India, China, and United States are and will remain the countries with largest number of diabetics [3].

In spite of several decades of research since 1940's when several studies linked diabetes to renal disease $[4,5]$, there are still large gaps in the knowledge and understanding of pathophysiology of diabetic nephropathy.

One of the intriguing controversies has been that which patients of diabetes (type 1/type 2 ) are predisposed and are likely to progress to diabetic nephropathy. Several studies have demonstrated that only about $40 \%$ of patients of Type 1 and Type 2 diabetes have renal involvement. These set of patients that progress to frank diabetic nephropathy have been labeled as "progressors" and the other set of patients that in spite of similar control of blood sugar and long-term poor glycemic control do not progress have been labeled as "nonprogressors" [6].

There has been a paradigm shift in the understanding of factors held responsible for this discrepancy in the natural history of these two sets of patients with the balance tilting towards hemodynamic factors rather than towards metabolic factors [7]. The other, controversy in diabetic nephropathy surrounds the concept of microalbuminuria. Albuminuria has been linked to diabetic renal disease as early as 1836 by Bright [8]. Several studies have established microalbuminuria as a hallmark of diabetic nephropathy and microalbuminuria has been used as a predictive marker for progressive decline in renal function [9-11], however few researchers 
have challenged its significance especially after studies showed that many patients of diabetic nephropathy with advanced renal disease never develop albuminuria [12-14] and also $58-68 \%$ patients with microalbuminuria regress over a period of time to normoalbuminuria $[15,16]$.

Another area of active research has been finding suitable markers for predicting which patients will progress. Many studies addressed biochemical markers but none is specific or sensitive enough for clinical use [17-19].

Of late researchers have tried to answer all these controversies by a single key and that is hemodynamic alterations [20] which include concepts of intraglomerular hypertension, raised renal vascular resistance and so called ischemic nephropathy, which have been held responsible for discrepancy in behavior of various groups; recently an article by Nosadini et al. established renal vascular resistance as a predictive marker for progressive disease [6].

Prompted with above considerations, we designed our study to evaluate renal vascular resistance with noninvasive Doppler in 57 diabetic patients attending a tertiary care centre in India.

\section{Material and Methods}

This study was carried out in the Department of Medicine and Radiology, Sir Sunderlal Hospital, Institute of Medical sciences (IMS), Banaras Hindu University (BHU) from May 2008 to June 2010 . The study protocol was approved by the research and ethical committee of the institute and written informed consent was taken from all patients.

A total 31 patients of diabetic nephropathy with stable disease, and three groups of control subjects (19 healthy subjects, 14 diabetics without microalbuminuria, and 12 diabetics with microalbuminuria) were included in the study. Diabetes was diagnosed as per WHO guidelines [21]. All of our patients were of type 2 diabetes. Diabetic nephropathy was labeled clinically satisfying the following criteria: (a) evidence of retinopathy on fundus examination, and (b) persistent albuminuria $>300 \mathrm{mg} / 24 \mathrm{hrs}$ or persistent proteinuria $>500 \mathrm{mg} / \mathrm{dl}$ on urine analysis on two separate occasions 3 months apart.

Microalbuminuria defined as $24 \mathrm{hr}$ urinary albumin 30 $300 \mu \mathrm{g} / \mathrm{dl}$. $24 \mathrm{hr}$ urinary collection was done from $8 \mathrm{AM}$ to $8 \mathrm{AM}$ next day with morning urine of day of start of collection discarded and morning urine of next morning collected. Adequacy of collection was confirmed by $24 \mathrm{hr}$ urinary creatinine estimation wherever necessary. Urine routine microscopy and urine cultures were done before estimation of $24 \mathrm{hr}$ urinary protein to rule out urinary tract infection. Patients with diabetic foot, valvular heart disease, ischemic heart disease, glomerulonephritis, lupus nephritis, renal calculi, hydronephrosis, renal masses, cerebrovascular, cardiovascular, and peripheral vascular disease were excluded.

\subsection{Doppler Study.}

(1) Pulsed Doppler study of interlobar and arcuate arteries was performed on bilateral kidneys.
Resistive Index (RI). Peak systolic frequency shift-minimum diastolic frequency shift/Peak systolic frequency shift during whole cardiac cycle.

Pulsatility Index (PI). Peak systolic frequency shift-minimum diastolic frequency shift/Mean frequency during the whole cardiac cycle.

We used a Toshiba NEMIO-30 Doppler machine and recorded findings with the help of a curvilinear probe of 3.75 Mhz. The sonologist was unaware of the group to which the patient belonged. RI and PI readings 2 each per vessel (interlobar arteries) for both kidneys were recorded and average of all 4 readings was taken for study purposes.

B mode ultrasound was also done to look for renal size length, breath, and thickness. Patients with anatomical renal artery stenosis of the renal artery (main) were excluded from the study. Wall filter was set to a minimum of $50 \mathrm{~Hz}$ and with a Doppler sample volume set at $2-4 \mathrm{~mm}$, minimum pulse repetition frequencies that did not produce aliasing were used with readings noted from existing software in the machine and all readings done at minimum possible angle between ultrasound beam and the vessel. Patients were rested for $5 \mathrm{~min}$ before taking any Doppler reading and all readings made while subject was lying in supine position with the breath held in deep end inspiration. Subjects were required to hold their breath while readings were being taken to obtain adequate spectral waveforms. Readings of RI and PI were made after a minimum of 4 identical consecutive spectral waveforms were achieved. Reproducibility of Doppler readings was assessed by intraobserver and interobserver variance which was $3.9 \%$ and $5.0 \%$, respectively.

Many subjects could not cooperate in the study and could not hold breaths adequately and were removed from the study especially patients with morbid obesity, respiratory problems, and so forth. This may be the reason for a nonintentional lower mean BMI values in our study population.

Blood pressure was recorded after a $5 \mathrm{~min}$ rest just before the Doppler examination in right arm supine position and a second reading was made $5 \mathrm{~min}$ after the Doppler examination was completed. Average values of both readings were recorded. Mean blood pressure was calculated for comparison purposes. A standard health questionnaire was completed which included type, duration of diabetes, treatment history, and other significant illness like hypertension and coronary artery disease were also enquired into.

Patients with proteinuria had to have proteinuria on two occasions three months apart; they were put on adequate and necessary treatment in the first visit and most of them continued treatment till the next visit, therefore labeling a patient as "on insulin" or "on OHA" or "on ACE/ARB" meant they were on that treatment for at least 3 months.

Other patient variables like age, 24 hour urinary protein/albumin, $\mathrm{HbAlc} \%$ values, fundus examination, lipid profile, and anthropometric measurements were also recorded. Serum glucose level (FBS, PPBS) was estimated by glucose oxidase/glucose peroxidase method and Serum lipid parameters (total cholesterol, HDL-C, LDL-C, very low density lipoprotein, and triglyceride) were quantified by commercially available Kits (Span diagnostics, India) 
TABLE 1: Baseline characteristics of different groups.

\begin{tabular}{|c|c|c|c|c|c|}
\hline Variable & $\begin{array}{l}\text { Diabetic nephropathy } \\
\text { (Group A) }(n=31)\end{array}$ & $\begin{array}{l}\text { Diabetics with } \\
\text { microalbuminuria } \\
(\text { Group B) } \\
(n=14)\end{array}$ & $\begin{array}{c}\text { Diabetics without } \\
\text { microalbuminuria } \\
(\text { Group C) } \\
(n=12)\end{array}$ & $\begin{array}{l}\text { Nondiabetic } \\
\text { controls } \\
(n=19)\end{array}$ & $P$-value \\
\hline $\begin{array}{l}\text { Age (yrs) } \\
\text { Median } \pm \mathrm{IQR}\end{array}$ & $58 \pm 14.25$ & $60 \pm 15$ & $58.50 \pm 15$ & $50.00 \pm 22.25$ & .059 (NS) \\
\hline Sex Ratio (M/F) & $20 / 11$ & $7 / 7$ & $10 / 2$ & $13 / 6$ & .351 (NS) \\
\hline $\begin{array}{l}\text { Duration of diabetes (yrs) } \\
\text { Median } \pm \mathrm{IQR}\end{array}$ & $7.00 \pm 11.25$ & $3.5 \pm 11.75$ & $2.5 \pm 19.25$ & - & .179 (NS) \\
\hline $\begin{array}{l}\mathrm{BMI}\left(\mathrm{Kg} / \mathrm{m}^{2}\right) \\
\text { Mean } \pm \mathrm{SD}\end{array}$ & $22.416 \pm 4.218$ & $22.451 \pm 4.007$ & $24.008 \pm 4.756$ & $21.872 \pm 3.974$ & .581 (NS) \\
\hline $\begin{array}{l}\text { Treatment diabetes } \\
\text { (OHA/Insulin) }\end{array}$ & $21 / 10$ & $9 / 5$ & $9 / 2$ & - & $.602(\mathrm{NS})$ \\
\hline $\begin{array}{l}\text { Treatment hypertension } \\
\text { (ACE or ARB/others) }\end{array}$ & $9 / 22$ & $8 / 6$ & $0 / 12$ & $1 / 18$ & $<.001$ \\
\hline $\begin{array}{l}\text { Serum Creatinine } \\
\text { Median } \pm \text { IQR }\end{array}$ & $1.9 \pm 2.1$ & $1.2 \pm 1.2$ & $1 \pm 0.4$ & $0.9 \pm 0.1$ & $<.001$ \\
\hline $\begin{array}{l}\text { GFR }(\mathrm{ml} / \mathrm{min}) \\
\text { Mean } \pm \mathrm{SD}\end{array}$ & $37.134 \pm 23.5$ & $48.383 \pm 21.042$ & $71.456 \pm 32.666$ & $78.455 \pm 18.96$ & $<.001$ \\
\hline $\begin{array}{l}\text { FBS }(\mathrm{mg} / \mathrm{dl}) \\
\text { Median } \pm \mathrm{IQR}\end{array}$ & $170 \pm 130.5$ & $180 \pm 100$ & $157 \pm 74.5$ & $78 \pm 15$ & $<.001^{*}$ \\
\hline $\begin{array}{l}\text { Hb1Ac (\%) } \\
\text { Median } \pm \text { IQR }\end{array}$ & $8.5 \pm 3.15$ & $8.0 \pm 2.2$ & $7.15 \pm 1.55$ & $4.1 \pm 0.3$ & $<.001^{*}$ \\
\hline $\begin{array}{l}\text { Cholesterol }(\mathrm{mg} / \mathrm{dl}) \\
\text { Median } \pm \mathrm{IQR}\end{array}$ & $106 \pm 28.5$ & $102.5 \pm 75$ & $73.5 \pm 44$ & $73 \pm 9.75$ & $<.001^{* *}$ \\
\hline $\begin{array}{l}\text { Triglyceride (mg/dl) } \\
\text { Median } \pm \text { IQR }\end{array}$ & $120 \pm 126$ & $127 \pm 153$ & $102 \pm 97.5$ & $88 \pm 20$ & .144 \\
\hline $\begin{array}{l}\text { Mean blood pressure }(\mathrm{mmHg}) \\
\text { Mean } \pm \mathrm{SD}\end{array}$ & $96.75 \pm 12.1$ & $97.95 \pm 10.5$ & $92.5 \pm 10.195$ & $97.36 \pm 16.16$ & 691 (NS) \\
\hline $\begin{array}{l}\text { Fundus staging (early/late) } \\
\text { Early = stage } 1 \& 2 \\
\text { Late }=\text { stage } 3 \& 4\end{array}$ & $19 / 12$ & $8 / 2^{*}$ & $3 / 0^{*}$ & - & $.256(\mathrm{NS})$ \\
\hline
\end{tabular}

${ }^{*}$ There was no significant difference between groups A, B, and C.

** There was no significant difference between A and B, but significant difference between A and C, and between B and C.

using manufacturer's protocol using Autoanalyzer (Flexor XL machine, Vitro sciences). HbAlc\% was measured in venous sample after an overnight fast by D10 Bio-rad system automated machine using HPL-C technique of electrophoresis. All the biochemical tests were performed in hospital's central biochemical laboratory.

Fundus examination was done by an ophthalmologist who did not know the group under which the patient felt. Staging of the disease was done according to International Clinical Diabetic Retinopathy Disease Severity Scale. We used the GAULT COCKROFT FORMULA to calculate GFR.

\section{Statistical Analysis}

All the data were reported as mean \pm standard deviation if they were normally distributed and as median \pm Inter Quartile Range (IQR) if they were not normally distributed. One way ANOVA was applied when comparing parametric variables (mean) between four groups. Kruskal-wallis one way Anova was used to compare median values between groups if data was not normally distributed. Pearson's correlation was used to see corelation of RI and PI with various variables. Multivariate linear and stepwise forward progression analysis was done using RI and PI as dependent variables and other variables as independent variables. Subgroup analysis was done using unpaired student's " $t$ "test between two groups. Chi square test was used for rates and proportions, however if $>20 \%$ values were under 5 , Fisher exact test was used. Mann Whitney test was used for nonparametric variables between two groups. $P$-value $<.05$ was ascribed as significant difference between groups. Data were analyzed by the sigma stat software version 3.5.

\section{Results}

The baseline characteristics showed that a significant difference between the groups existed in serum cholesterol, GFR, and treatment of hypertension. Patients with diabetic nephropathy and diabetics with microalbuminuria had higher levels of serum cholesterol than patients without microalbuminuria. GFR showed progressive decline from diabetes without albuminuria to diabetic nephropathy. 
TABLE 2: Comparison of RI and PI between groups.

\begin{tabular}{|c|c|c|c|c|c|}
\hline & $\begin{array}{c}\text { Diabetic } \\
\text { nephropathy }\end{array}$ & $\begin{array}{c}\text { Diabetics with } \\
\text { microalbuminuria }\end{array}$ & $\begin{array}{l}\text { Diabetics without } \\
\text { microalbuminuria }\end{array}$ & $\begin{array}{c}\text { Nondiabetic } \\
\text { controls }\end{array}$ & $P$-value \\
\hline $\begin{array}{l}\text { RI } \\
\text { Median } \pm \mathrm{IQR}\end{array}$ & $0.825 \pm 0.178$ & $0.742 \pm 0.21$ & $0.74 \pm 0.169$ & $0.64 \pm 0.097$ & $<.001$ \\
\hline $\begin{array}{l}\text { PI } \\
\text { Median } \pm \text { IQR }\end{array}$ & $1.86 \pm 0.82$ & $1.388 \pm 0.67$ & $1.263 \pm 0.35$ & $1.075 \pm 0.39$ & $<.001$ \\
\hline
\end{tabular}

TABLE 3: Correlation of RI and PI with various variables.

\begin{tabular}{llcc}
\hline Index & Parameter & Correlation coefficient & $P$-value \\
\hline RI & Age & 0.329 & .003 \\
PI & Age & 0.383 & .000 \\
RI & BMI & -0.0235 & .840 \\
PI & BMI & 0.0221 & .849 \\
RI & Duration & -0.149 & .266 \\
PI & Duration & 0.0005 & .997 \\
RI & Diastolic blood pressure & -0.002 & .985 \\
PI & Diastolic blood pressure & -0.032 & .78 \\
RI & Systolic blood pressure & 0.0265 & .820 \\
PI & Systolic blood pressure & -0.0188 & .871 \\
RI & Mean blood pressure & 0.001 & .988 \\
PI & Mean blood pressure & -0.0385 & .740 \\
RI & Fasting Blood sugar & -0.145 & .281 \\
PI & Fasting Blood sugar & -0.178 & .183 \\
RI & Cholesterol & -0.162 & .227 \\
PI & Cholesterol & -0.0475 & .725 \\
RI & Triglyceride & -0.143 & .289 \\
PI & Triglyceride & -0.129 & .339 \\
RI & Serum creatinine & 0.368 & .001 \\
PI & Serum creatinine & 0.479 & .000 \\
RI & GFR & -0.456 & .000 \\
PI & GFR & -0.534 & .000 \\
RI & Fundus stage & 0.425 & .001 \\
PI & Fundus stage & 0.525 & .000 \\
\hline & & &
\end{tabular}

Patients with diabetes without microalbuminuria although had mean values lower than control population but there were values above values in normal population signifying presence of hyperfiltration early in diabetes. Patients in diabetic nephropathy group had 9 patients receiving ACE/ARB, others were receiving other antihypertensive as either these patients had contraindications to use of this drug or could not tolerate the drug. Higher percentages of patients in diabetes with microalbuminuria group were on ACE inhibitors. Patients in this group who were not on ACE inhibitors were again those in whom it was contraindicated or not tolerated or patients who did not comply with the advised treatment. Duration of disease was not significantly different in the various groups signifying that in spite of long duration of diabetes many patients did not develop diabetic nephropathy and still remained in the group of diabetes without microalbuminuria, the median duration of disease in this group was $2.5 \pm 19.25 \mathrm{yrs}$, which was nonsignificantly lower than other groups (Table 1).
TABLE 4: Comparison of patients with or without raised vascular resistance.

\begin{tabular}{lccc}
\hline Characteristics & R.I $\geq 0.8(n=30)$ & $\begin{array}{l}\text { RI }<0.8 \\
(n=27)\end{array}$ & $P$ value \\
\hline $\begin{array}{l}\text { Age } \\
\text { Mean } \pm \text { SD }\end{array}$ & $59.467 \pm 10.837$ & $56.11 \pm 8.243$ & .198 \\
\hline Sex ratio (M/F) & $19 / 11$ & $18 / 9$ & .988 \\
\hline $\begin{array}{l}\text { BMI } \\
\text { Median } \pm \text { IQR }\end{array}$ & $21.458 \pm 3.895$ & $22.862 \pm 6.431$ & .179 \\
\hline $\begin{array}{l}\text { Duration } \\
\text { Median } \pm \text { IQR }\end{array}$ & $5 \pm 9$ & $10 \pm 19$ & .381 \\
\hline $\begin{array}{l}\text { Mean B.P. } \\
\text { (Mean } \pm \text { SD) }\end{array}$ & $95.289 \pm 12.508$ & $97.11 \pm 10.005$ & .549 \\
\hline $\begin{array}{l}\text { FBS } \\
\text { Median } \pm \text { IQR }\end{array}$ & $160 \pm 88$ & $170 \pm 88.5$ & .406 \\
\hline $\begin{array}{l}\text { Fundus staging } \\
\text { (early/late) }\end{array}$ & $20 / 10$ & $22 / 4$ & .216 \\
$\begin{array}{l}\text { Early }=\text { stage 0, } 1 \& 2 \\
\text { Late }=\text { stage 3\&4 }\end{array}$ & & & .399 \\
\hline $\begin{array}{l}\text { GFR } \\
\text { Mean } \pm \text { SD }\end{array}$ & $42.741 \pm 24.043$ & $50.79 \pm 29.474$ & .261 \\
\hline $\begin{array}{l}\text { Treatment category } \\
\text { (OHA/Insulin) }\end{array}$ & $26 / 4$ & $14 / 13$ & .010 \\
\hline $\begin{array}{l}\text { Treatment } \\
\text { hypertension } \\
\text { (ON ACE or } \\
\text { ARB/others) }\end{array}$ & $8 / 22$ & $11 / 16$ & \\
\hline
\end{tabular}

The mean resistive index $(\mathrm{RI})$ values of interlobar arteries showed a statistically significant difference $(P<.001)$ between each group except between group $B$ and group $C$ that is no significant difference was seen between subjects with microalbuminuria and subjects without microalbuminuria. This would imply that RI values start increasing in diabetic subjects even before appearance of microalbuminuria.

The mean values of pulsatility index (PI) of interlobar arteries were also statistically significantly raised as compared to nondiabetics $(P<.001)$ but intragroup differences were significant only between subjects with diabetic nephropathy and diabetics without microalbuminuria (Table 2).

$\mathrm{RI}$ and PI on univariate analysis correlated significantly with age, serum creatinine, GFR, stage of diabetic retinopathy, and treatment group for diabetes; patients on insulin having lower values of RI and PI, on multivariate linear analysis and multivariate stepwise forward progression using RI and PI as dependent variable RI and PI correlated with age, serum creatinine, and GFR (Table 3 ). 
TABLE 5: Comparison of patients between treatment groups.

\begin{tabular}{|c|c|c|c|}
\hline Characteristics & $\begin{array}{c}\text { On } \\
\text { insulin* }(n=17)\end{array}$ & $\begin{array}{c}\text { On OHA* } \\
(n=40)\end{array}$ & $P$-value \\
\hline $\begin{array}{l}\text { Age } \\
\text { Mean } \pm \text { SD }\end{array}$ & $57 \pm 7.508$ & $58.25 \pm 10.636$ & .662 \\
\hline Sex ratio $(M / F)$ & $10 / 7$ & $27 / 13$ & .745 \\
\hline $\begin{array}{l}\text { BMI } \\
\text { Mean } \pm \text { SD }\end{array}$ & $23.652 \pm 4.014$ & $22.381 \pm 4.35$ & .307 \\
\hline Duration & $10 \pm 19.188$ & $5 \pm 11$ & .88 \\
\hline $\begin{array}{l}\text { Mean B.P } \\
\text { Mean } \pm \text { SD }\end{array}$ & $96.039 \pm 11.699$ & $96.2 \pm 11.391$ & .961 \\
\hline $\begin{array}{l}\text { Hb1Ac } \\
\text { Median } \pm \mathrm{IQR}\end{array}$ & $8.3 \pm 2.7$ & $7.55 \pm 2.6$ & .341 \\
\hline $\begin{array}{l}\text { FBS } \\
\text { Median } \pm \mathrm{IQR}\end{array}$ & $200 \pm 117$ & $160.5 \pm 76.5$ & .140 \\
\hline $\begin{array}{l}\text { Fundus staging } \\
\text { (early/late) } \\
\text { Early = stage } 0, \\
1 \& 2 \\
\text { Late = stage } 3 \& 4\end{array}$ & $13 / 4$ & $30 / 10$ & 1 \\
\hline $\begin{array}{l}\text { GFR } \\
\text { Mean } \pm \text { SD }\end{array}$ & $51.889 \pm 32.596$ & $45.725 \pm 25.164$ & .443 \\
\hline $\begin{array}{l}\text { Treatment } \\
\text { hypertension } \\
\text { (ON ACE or } \\
\text { ARB/others) }\end{array}$ & $8 / 9$ & $11 / 29$ & .260 \\
\hline $\begin{array}{l}\text { RI } \\
\text { Median } \pm \mathrm{IQR}\end{array}$ & $0.703 \pm 0.117$ & $0.835 \pm 0.182$ & .001 \\
\hline $\begin{array}{l}\text { PI } \\
\text { Median } \pm \text { IQR }\end{array}$ & $1.33 \pm 0.490$ & $1.742 \pm 0.974$ & .094 \\
\hline $\begin{array}{l}\begin{array}{l}\text { Proteinuria } \\
\text { (mg/day) }\end{array} \\
\text { Median } \pm \mathrm{IQR}\end{array}$ & $600 \pm 2862$ & $540.5 \pm 648$ & .291 \\
\hline
\end{tabular}

There was also significant co relation of stage of retinal disease with RI and PI values $(P<.001)$ (Spearman co relation coefficient). On multiple comparison tests there was significant difference between RI values of stage 4 versus normal and Stage 2 versus normal; PI also correlated with stage of fundal disease with higher values in higher retinal stage $(P<.001)$. On multiple comparison tests there was significant difference between PI values of stage 4 versus normal, Stage 3 versus normal, stage 2 versus normal, and stage 2 versus stage 1 .

Subgroup analysis of diabetic subjects on basis of RI values showed that the groups differed significantly only in the treatment received for diabetes with patients with significant proportion of patients with RI $<0.8$ on Insulin therapy (Table 4).

On classifying diabetic patients according to treatment received patients on insulin therapy had significantly lower values of RI than patients on OHA's in spite of having similar blood sugar controls in form of almost same $\mathrm{HbAlc} \%$ levels. However fasting blood sugar levels were significantly higher in patients on insulin. Therefore in spite of equal or even poor glycemic control patients on insulin had lower RI values. PI values were also nonsignificantly lower in patients on insulin (1.33 versus 1.74) (Table 5).

\section{Discussion}

Our study did not show any co relation of RI or PI values with BMI, Sex, FBS, HbAlc, serum cholesterol, serum triglyceride, duration of disease, or mean blood pressure. Barring a few studies our results are in accordance with many similar studies on this topic. These findings suggest that there are factors other than the level of metabolic control that contribute to diabetic nephropathy and raised renal vascular resistance in these patients. Haemodynamic factors like blood pressure control could explain these variations but studies have shown conflicting results. Ishimura et al. [22] showed no correlation between RI and PI values and mean blood pressure however Kim et al. [23] showed a significant co relation of RI and PI values with mean blood pressure.

Our study showed significant co relation of RI and PI values with serum creatinine and eGFR. GFR of subjects with microalbuminuria was significantly lower than subjects without proteinuria. This emphasizes the point that microalbuminuria is not a very good marker for early detection of diabetic nephropathy since fall in GFR has already set in once microalbuminuria develops, and hence the need to identify a more early marker.

RI and PI values of all diabetics were $0.805 \pm 0.187$ and $1.63 \pm 0.831$, which was significantly higher than that of controls. Intragroup comparison showed significant differences between groups except between groups with and without microalbuminuria, that is, RI was raised even before microalbuminuria started. There were 2 patients with serum creatinine $>1.5$, that is, with already set-in renal failure but still no microalbuminuria. No correlation of RI or PI was found with amount of proteinuria on univariate analysis. Kim et al. [23] cited a significant correlation of 24-hour protein value with RI Hamano et al. [24] did not show any correlation with amount of proteinuria as a continuous variable on univariate analysis. However both Hamano et al. [24] and Ljubiæ et al. [25] showed significant correlation of RI with proteinuria on multivariate stepwise regression analysis.

Another issue that has been addressed in various studies is that diabetic nephropathy has been demonstrated to have higher renal vascular resistance than other causes of CKD [26]. This led to the postulation that there is some specific pathophysiology to diabetes that causes this raised renal vascular resistance. Although diabetic nephropathy has been classically described as a microvascular complication, however there is another school of thought that thinks that diabetic nephropathy and raised renal resistance are a part of accelerated diffuse atherosclerotic process and widespread endothelial dysfunction that accompanies diabetes. This is based on several observations that renal vascular resistance is particularly higher in patients with lower limb vascular disorders in diabetes. Also pathological studies have shown arterial sclerosis in kidney biopsy of medium-sized arteries perpendicular to the kidney surface. Therefore several studies have tried to correlate RI and PI with markers of macrovascular disease such as Carotid intimo-medial thickness (IMT) and aortic stiffness parameters like brachial ankle pulse wave velocity (ba-PWV) and ankle brachial pressure index (ABI). 
In our study we excluded patients with macrovascular complications and still found significant higher RI values. We also demonstrated a significant correlation of stage of retinal disease with RI \& PI values which itself is a microvascular complication. There was significant difference between RI \& PI values of stage 4 versus normal, stage 2 versus normal, and stage 2 versus stage 1 . PI also corelated with stage of fundal disease with higher values in higher retinal stage. This suggests that raised renal vascular resistance starts due to diabetic microvascular pathophysiology and at a later date may get accelerated due to accompanying macro vascular complication.

Therefore we from above findings conclude that RI and PI as an indices of renal vascular resistance are an early marker for recognition of diabetic nephropathy and also are predictive factorsof recognition of patients at risk for future development of diabetic nephropathy. However this exercise is useful only if we have measures to retard progression of these patients to diabetic nephropathy. One of the useful interventions is ACE/ARB, which in numerous studies have shown beneficial effect on prognosis of diabetic nephropathy. In our study diabetic patients on ACE/ARB had significantly lower PI values than patients not on ACE/ARB and nonsignificantly lower RI values; in spite of similar age, blood pressure, and glycemic control.

Another important finding of our study was that patients on insulin had significantly lower RI and PI values, in spite of similar age, blood sugar and blood pressure control, and proteinuria. Several studies indicate that insulin deficiency per se contributes to the neovascularization, increased surface area and afferent arteriolar dilation in diabetes. Several studies show that physiological concentrations of insulin cause afferent arteriolar constriction and efferent arteriolar dilation. These observations strongly support the notion that insulin deficiency directly contributes, at least in part, to the glomerular hypertension in diabetes. Some studies have addressed differential class effect of antidiabetic drugs on renal vascular resistance. Of note is a study by Pistrosch et al. [27], which concluded that rosiglitazone an insulin sensitizer had beneficial effect on renal vascular resistance as well as endothelial dysfunction.

However our study has certain limitations in the form of small sample size, a hospital-based sample, and crosssectional nature of the study; hence large longitudinal population-based studies are required before any clinically meaningful outcomes can be derived from our observations.

\section{References}

[1] O. E. Ayodele, C. O. Alebiosu, and B. L. Salako, "Diabetic nephropathy - a review of the natural history, burden, risk factors and treatment," Journal of the National Medical Association, vol. 96, no. 11, pp. 1445-1454, 2004.

[2] M. K. Mani, "Patterns of renal disease in indigenous populations in India," Nephrology, vol. 4, supplement, pp. S4-S7, 1998.

[3] H. King, R. E. Aubert, and W. H. Herman, "Global burden of diabetes, 1995-2025: prevalence, numerical estimates, and projections," Diabetes Care, vol. 21, no. 9, pp. 1414-1431, 1998.
[4] P. Kimmelstiel and C. Wilson, "Intercapillary lesions in the glomeruli of the kidney," American Journal of Pathology, vol. 12, no. 1, pp. 83-98, 1936.

[5] J. S. Cameron, "The discovery of diabetic nephropathy: from small print to centre stage," Journal of Nephrology, vol. 19, no. 10, supplement, pp. S75-S87, 2006.

[6] R. Nosadini, M. Velussi, E. Brocco et al., "Course of renal function in type 2 diabetic patients with abnormalities of albumin excretion rate," Diabetes, vol. 49, no. 3, pp. 476-484, 2000.

[7] R. Zatz, T. W. Meyer, H. G. Rennke, and B. M. Brenner, "Predominance of hemodynamic rather than metabolic factors in the pathogenesis of diabetic glomerulopathy," Proceedings of the National Academy of Sciences of the United States of America, vol. 82, no. 17, pp. 5963-5967, 1985.

[8] R. Bright, "Cases and observations illustrative of renal disease accompanied with the secretion of albuminous urine," Guy's Hospital Reports, vol. 1, no. 1, pp. 338-400, 1836.

[9] M. A. Gall, P. Hougaard, K. Borch-Johnsen, and H. H. Parving, "Risk factors for development of incipient and overt diabetic nephropathy in patients with non-insulin dependent diabetes mellitus: prospective, observational study," British Medical Journal, vol. 314, no. 7083, pp. 783-788, 1997.

[10] C. E. Mogensen, "Microalbuminuria predicts clinical proteinuria and early mortality in maturity-onset diabetes," The New England Journal of Medicine, vol. 310, no. 6, pp. 356-360, 1984.

[11] G. C. Viberti, R. J. Jarrett, and R. D. Hill, "Microalbuminuria as a predictor of clinical nephropathy in insulin-dependent diabetes mellitus," The Lancet, vol. 1, no. 8287, pp. 1430-1432, 1982.

[12] M. L. Caramori, P. Fioretto, and M. Mauer, "Low glomerular filtration rate in normoalbuminuric type 1 diabetic patients: an indicator of more advanced glomerular lesions," Diabetes, vol. 52, no. 4, pp. 1036-1040, 2003.

[13] J. M. Steinke, A. R. Sinaiko, M. S. Kramer, S. Suissa, B. M. Chavers, and M. Mauer, "The early natural history of nephropathy in type 1 diabetes: III. Predictors of 5-year urinary albumin excretion rate patterns in initially normoalbuminuric patients," Diabetes, vol. 54, no. 7, pp. 2164-2171, 2005.

[14] H. J. Kramer, Q. D. Nguyen, G. Curhan, and C. Y. Hsu, "Renal insufficiency in the absence of albuminuria and retinopathy among adults with type 2 diabetes mellitus," Journal of the American Medical Association, vol. 289, no. 24, pp. 3273-3277, 2003.

[15] H. H. Parving, N. Chaturvedi, G. Viberti, and C. E. Mogensen, "Does microalbuminuria predict diabetic nephropathy?" Diabetes Care, vol. 25, no. 2, pp. 406-407, 2002.

[16] B. A. Perkins, L. H. Ficociello, K. H. Silva, D. M. Finkelstein, J. H. Warram, and A. S. Krolewski, "Regression of microalbuminuria in type 1 diabetes," The New England Journal of Medicine, vol. 348, no. 23, pp. 2285-2293, 2003.

[17] H. H. Otu, H. Can, D. Spentzos et al., "Prediction of diabetic nephropathy using urine proteomic profiling 10 years prior to development of nephropathy," Diabetes Care, vol. 30, no. 3, pp. 638-643, 2007.

[18] B. A. Perkins, R. G. Nelson, B. E. P. Ostrander et al., "Detection of renal function decline in patients with diabetes and normal or elevated GFR by serial measurements of serum cystatin C concentration: results of a 4-year follow-up study," Journal of the American Society of Nephrology, vol. 16, no. 5, pp. 14041412, 2005.

[19] D. Ellis, K. Y. Z. Forrest, J. Erbey, and T. J. Orchard, "Urinary measurement of transforming growth factor- $\beta$ and type IV 
collagen as new markers of renal injury: application in diabetic nephropathy," Clinical Chemistry, vol. 44, no. 5, pp. 950-956, 1998.

[20] R. H. Noth, A. Krolewski, G. A. Kaysen, T. W. Meyer, and M. Schambelan, "Diabetic nephropathy: hemodynamic basis and implications for disease management," Annals of Internal Medicine, vol. 110, no. 10, pp. 795-813, 1989.

[21] World Health Organization, "Definition, Diagnosis and Classification of Diabetes Mellitus and its Complications, Report of a WHO Consultation Part 1: Diagnosis and Classification of Diabetes Mellitus," World Health Organization Department of Non communicable Disease Surveillance, Geneva, Switzerland, 1999.

[22] E. Ishimura, Y. Nishizawa, T. Kawagishi et al., "Intrarenal hemodynamic abnormalities in diabetic nephropathy measured by duplex Doppler sonography," Kidney International, vol. 51, no. 6, pp. 1920-1927, 1997.

[23] S. H. Kim, H. Kim, S. Y. Kim et al., "Usefulness of R.I. and P.I. in patient with diabetic nephropathy as early markers," Korean Journal of Nephrology, vol. 19, no. 5, pp. 876-883, 2000.

[24] K. Hamano, A. Nitta, T. Ohtake, and S. Kobayashi, "Associations of renal vascular resistance with albuminuria and other microangiopathy in type 2 diabetic patients," Diabetes Care, vol. 31, no. 9, pp. 1853-1857, 2008.

[25] S. Ljubiæ, B. Brkljaèiæ, Z. Metelko, and I. P. Renar, "Renal resistance index in type 2 diabetes," Diabetologia Croatica, vol. 35, no. 1, pp. 7-13, 2006.

[26] Y. Ohta, K. Fuj II, H. Arima et al., "Increased renal resistive index in atherosclerosis and diabetic nephropathy assessed by Doppler sonography," Journal of Hypertension, vol. 23, no. 10, pp. 1905-1911, 2005.

[27] F. Pistrosch, K. Herbrig, B. Kindel, J. Passauer, S. Fischer, and P. Gross, "Rosiglitazone improves glomerular hyperfiltration, renal endothelial dysfunction, and microalbuminuria of incipient diabetic nephropathy in patients," Diabetes, vol. 54, no. 7 , pp. 2206-2211, 2005. 


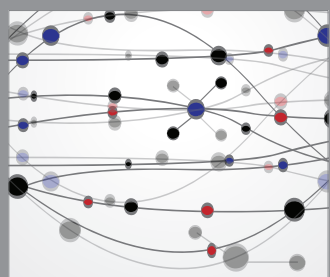

The Scientific World Journal
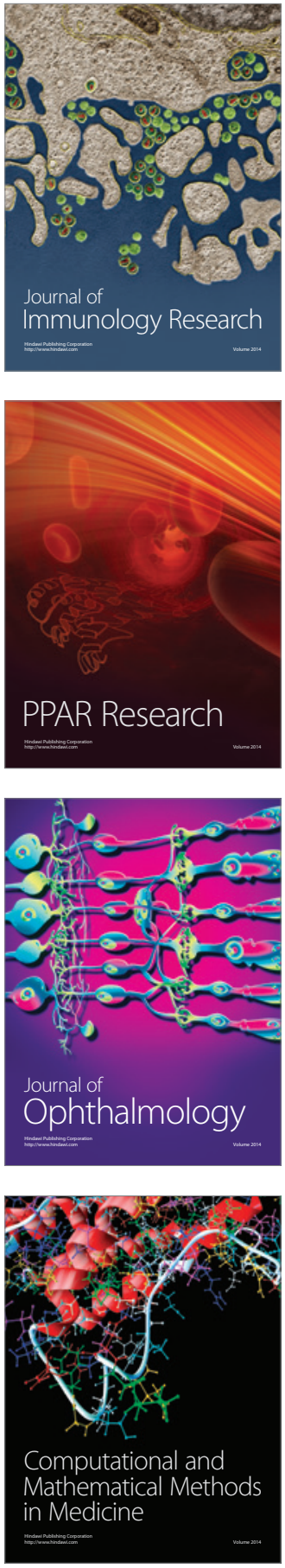

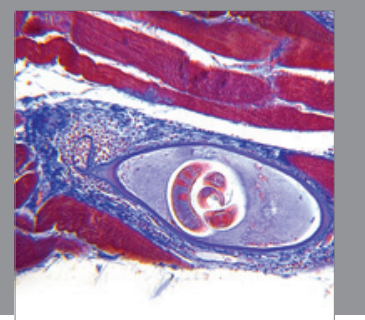

Gastroenterology

Research and Practice
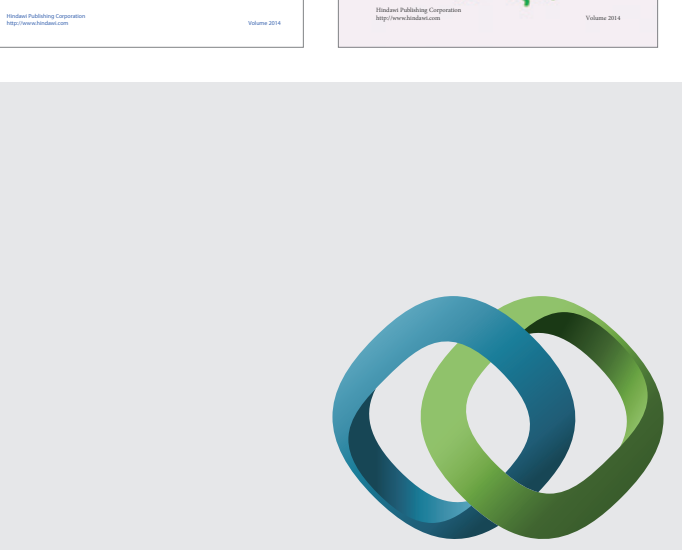

\section{Hindawi}

Submit your manuscripts at

http://www.hindawi.com
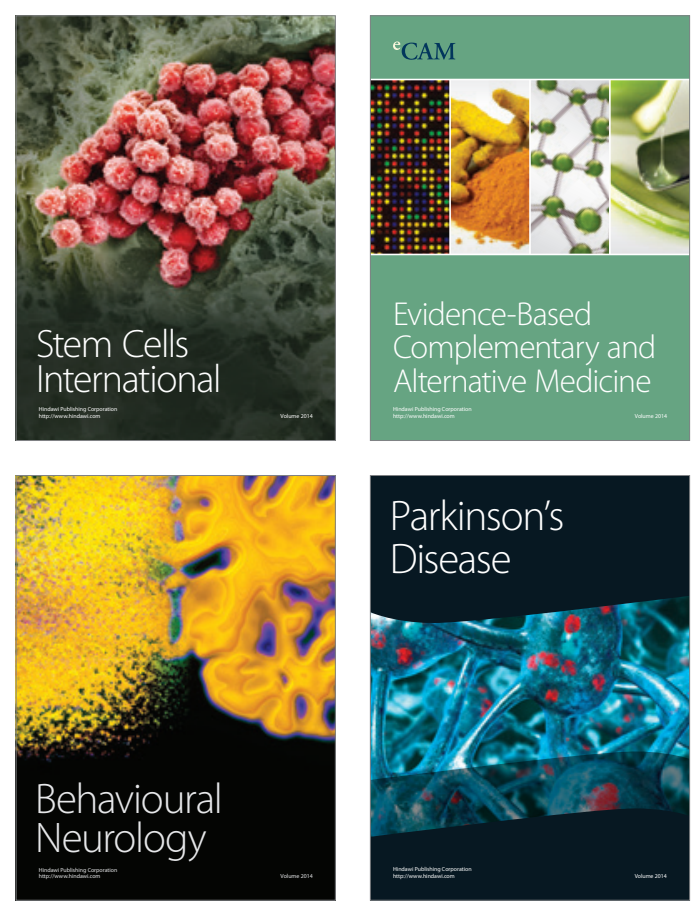

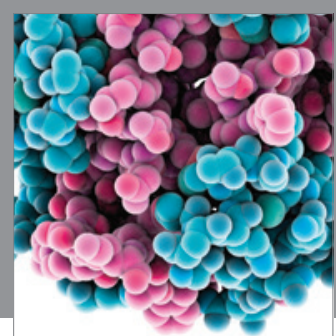

Journal of
Diabetes Research

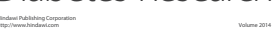

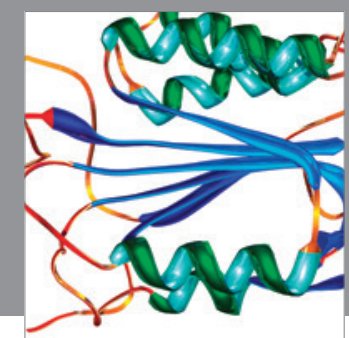

Disease Markers
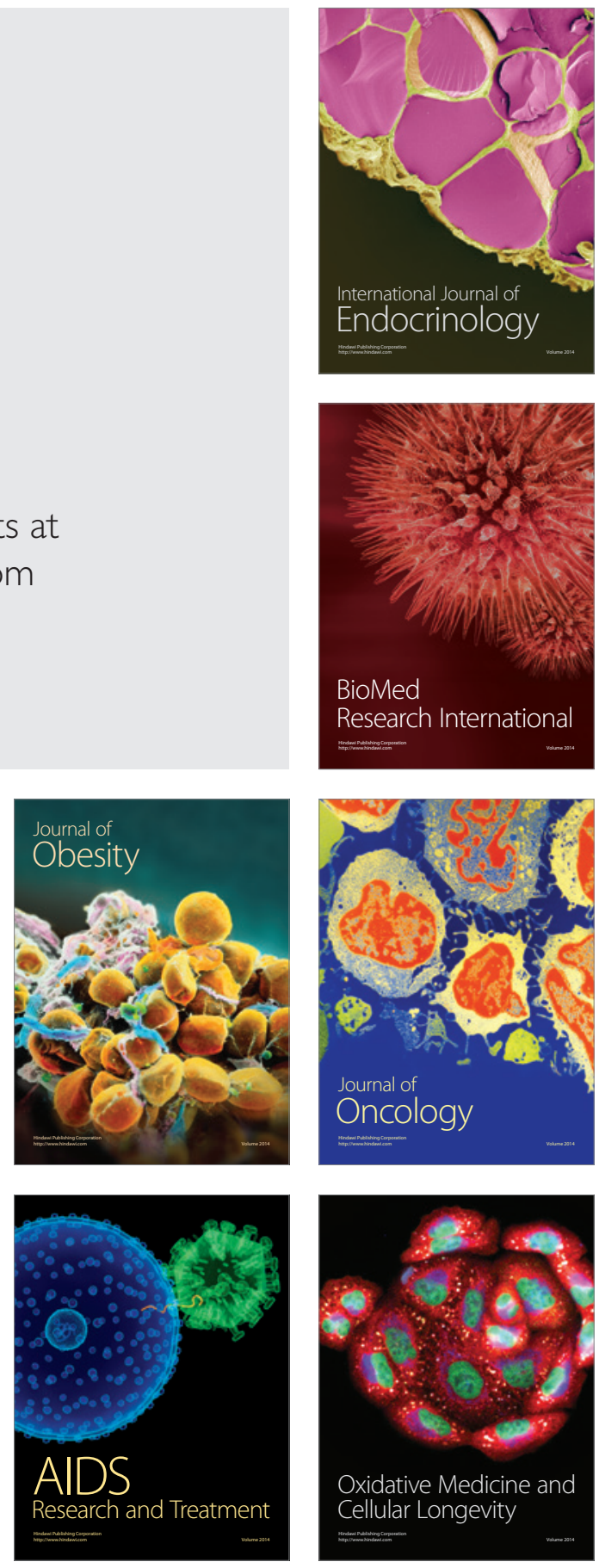